\title{
Prevention of Infectious Diseases in Athletes
}

\author{
Anthony Luke, MD, $\mathrm{MPH}^{\mathrm{a}, *}$, Pierre d'Hemecourt, $\mathrm{MD}^{\mathrm{b}}$ \\ ${ }^{a}$ Departments of Orthopaedic Surgery and Family and Community Medicine, \\ Primary Care Sports Medicine, University of California San Francisco, 500 Parnassus Ave., \\ MU-320W, San Francisco, CA 94143-0728, USA \\ 'Primary Care Sports Medicine, Harvard University, Children's Hospital of Boston, \\ 319 Longwood Ave., Boston, MA 02115, USA
}

l nfections in sports can be serious medical problems. They can affect individual athletes, resulting in morbidity and decreased performance [1]. They can also be spread to other athletes, putting them at risk for similar disease and complications. The sports medicine physician may face challenging issues regarding infectious diseases when dealing with teams or highly competitive athletes who have difficulties taking time off to recover. One must treat the individual sick athlete and take the necessary precautions to contain the spread of communicable disease to the surrounding team, staff, relatives, and other contacts.

The authors aim to translate recommendations in public health to practice in a sports medicine setting. Sports physicians have an opportunity to see athletes during adolescence and adulthood who might not come in for routine health maintenance except when related to their sports. Primary prevention of infectious disease, the ideal goal, deals with avoiding the development of the disease before infection occurs. Immunizations are an example of primary prevention and have been the most successful public health programs for disease prophylaxis. Secondary prevention for infection control involves prevention of spread to others. Athletes are often exposed to many different people, travel to compete in various environments locally and internationally, and engage in higher-risk activities, often in close contact with others [2]. The authors discuss the preventive strategies for infectious disease in sport, including (1) a review of immunization recommendations and prophylaxis guidelines, (2) improvements in personal hygiene and prevention of spread of infectious organisms by direct contact, (3) insect-borne disease precautions, and (4) prevention of sexually transmitted diseases (STDs). A special emphasis on immunizations focuses on pertussis, influenza, and meningococcal prophylaxis.

*Corresponding author. E-mail address: lukea@orthosurg.ucsf.edu (A. Luke). 


\section{PUBLIC HEALTH, INFECTIOUS DISEASES, AND SPORTS}

Public health plays an insidious role in our everyday lives to keep individuals safe from communicable diseases, accidents, environmental concerns, and countless other dangers. Programs are most successful when a disease no longer becomes a worry for the population through active prevention strategies. Much of our understanding comes from history and from recognizing the imminent dangers so we can prevent diseases from occurring the next time.

Medical reports from major athletic events provide examples of issues that can be encountered by the sports medicine physician. Mass-gathering events, such as the Olympics, highlight some of the concerns that can occur with sports and infectious diseases. International athletes compete together from countries with different endemic microorganisms and variable health care practices. For example, an outbreak of measles occurred in a Special Olympics event in St. Paul, Minnesota. The point of infection was suspected to be a track and field athlete from Argentina, resulting in measles infections in 16 individuals from 7 different states [3]. An outbreak of influenza that occurred during the 1988 Calgary Olympics was believed to have possibly affected the performances of some athletes [4]. The pneumococcal vaccine was recommended to athletes before competing in the 1992 Barcelona Olympics because of resistant Streptococcus pneumoniae strains endemic in Spain [5]. Medical reporting and surveillance of infections are extremely important to attempt to contain spread of disease. At the 1996 Atlanta Olympics, a priority of surveillance was to identify unusual presentations and infectious disease outbreaks to actively implement same-day medical and public health interventions [6].

It is an important responsibility of physicians to report specific infectious diseases, especially if an outbreak is suspected (Box 1) [7]. Health professionals should contact their local public health officer to determine whether other cases are occurring and what precautions need to be taken in the event of a serious outbreak. In the past few years, infections such as severe acute respiratory syndrome [8] have required the need of quarantine to help control the spread of these dangerous diseases. Health care professionals should report all clinically significant adverse events following immunization to the Vaccine Adverse Events Reporting System [9].

\section{ATHLETES ARE "HIGHER RISK"}

The risk of disease transmission depends on the infectious agent-for example, whether it is spread by way of respiratory secretions, skin contact, or blood. In the context of infections spread by aerosol droplets, "close contact" can mean caring for or living with an infected patient or having a high likelihood of direct contact with the respiratory secretions or body fluids of an infected patient. Examples of close contact include kissing or embracing, sharing eating or drinking utensils, talking to someone within $3 \mathrm{ft}$, physical examination, and any other direct physical contact between people. Close contact does not include activities such as walking by a person or briefly sitting across from someone [10]. 


\section{Box 1: Infectious diseases designated as notifiable at the national level during 2004}

Acquired immunodeficiency syndrome (AIDS)

Anthrax

Botulism

Brucellosis

Chancrodi

Chlamydia trachomatis, genital infection

Cholera

Coccidioidomycosis

Cryptosproidiososis

Cryptosporidiosis

Cyclosporiasis

Diphtheria

Ehrlichiosis

Human granulocytic

Human monocytic

Human, other or unspecified agent

Encephalitis/meningitis, arboviral

California serogroup

Eastern equine

Powassan

St. Louis

Western equine

West Nile

Enterohemorrhagic Escherichia coli (EHEC)

EHEC O157:H7

EHEC Shiga toxin-positive, serogroup non-O157

EHEC Shiga toxin-positive, not serogrouped

\section{Giardiasis}

Gonorrhea

Haemophilus influenzae, invasive disease

Hansen disease (leprosy)

Hantavirus pulmonary syndrome

Hemolytic uremic syndrome, postdiarrheal

Hepatitis A, viral, acute

Hepatitis $B$, viral, acute 


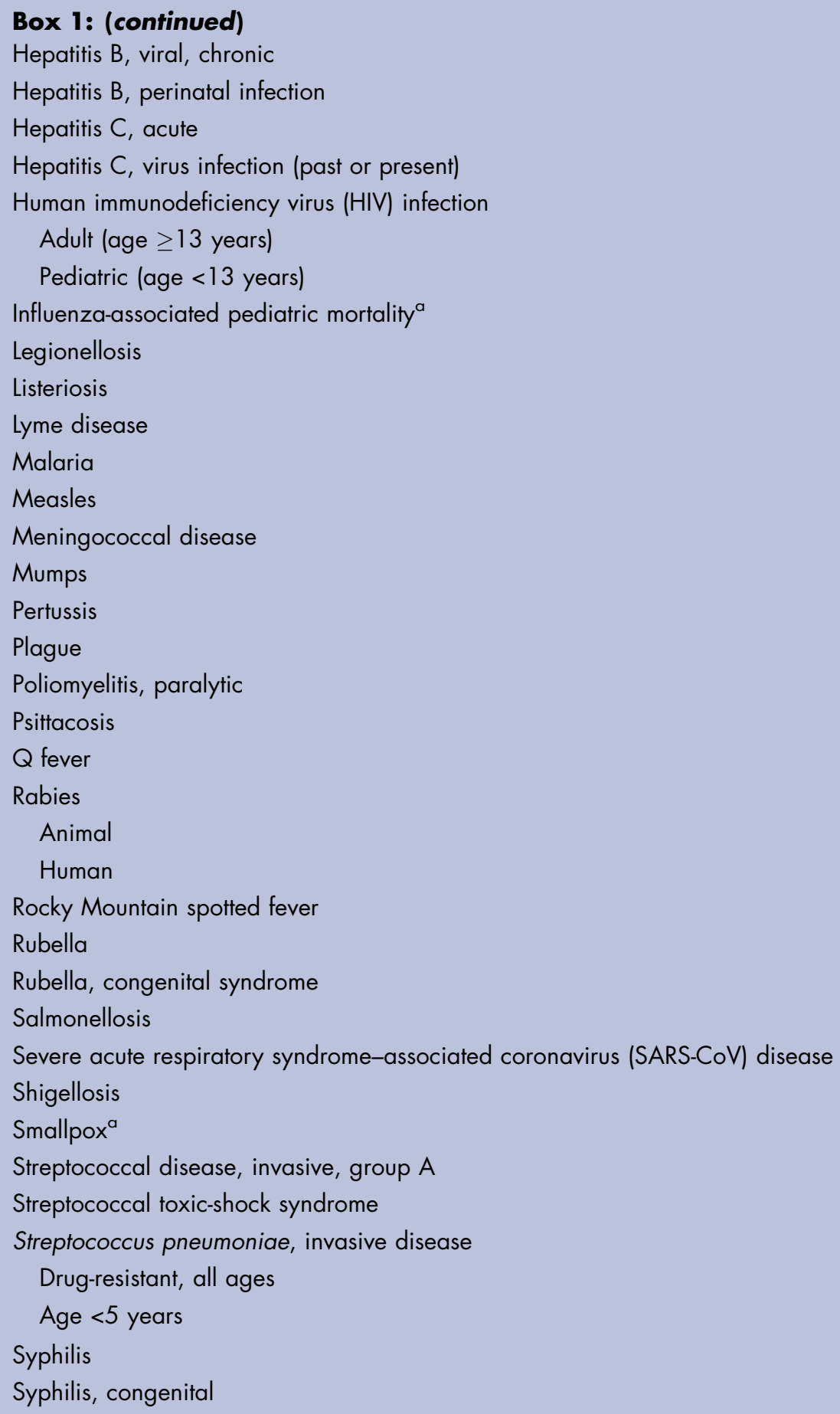




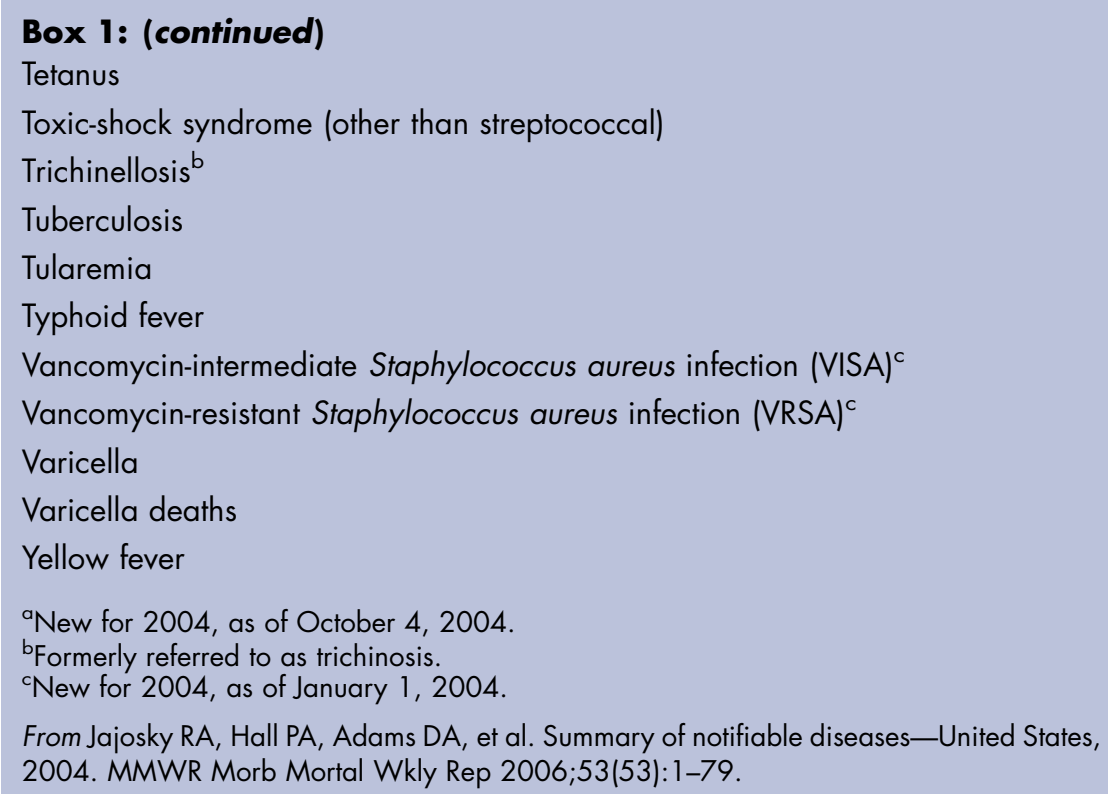

Athletes may share personal items (eg, towels, water bottles, and soap) and equipment (eg, weights). They may live in dormitories or in hotel rooms while traveling, which leads to close contact and high exposure to teammates. They participate in higher-risk activities $[2,11]$. Fewer athletes practice safe sex, which can lead to STDs in homosexual and in heterosexual individuals. Athletes also use more illicit drugs and alcohol, which can place them at risk of intravenous needle exposure $[12,13]$. Steroids, hormones, and vitamins are other substances that some athletes are injecting $[14,15]$. Tattoos are popular among athletes, which are another source of needle infection risk.

\section{IMMUNIZATIONS}

Active immunization involves the administration of all or part of a microorganism or a modified product of that microorganism, such as an antigen or protein. This administration stimulates an immune response to develop protection against future exposure to the infection [16]. Although most vaccines are over $90 \%$ effective, they are not guaranteed to promote immune protection [16].

Immunizations typically involve inactivated vaccines or live, attenuated viruses. Inactivated vaccines include killed virus or bacterial proteins to stimulate one's immune system to develop antibodies to any similar virus or bacteria. More side effects are associated with the live, attenuated viruses-typically local pain and, rarely, hypersensitivity reactions to vaccine constituents. A mild febrile illness, a recent exposure to an infectious disease, pregnancy, breastfeeding, nonspecific allergies, and family history of an adverse event after immunization, including seizures, are NOT contraindications for immunization [16]. 
Sports medicine physicians need to consider the following indications for immunizations (Tables 1 and 2): (1) routine health maintenance; (2) catch-up immunizations for failed or missed immunizations; (3) immunizations of high risk groups (ie, splenectomy, chronic disease, immunocompromised); (4) travel to an endemic area; (5) close contact with an infected individual, or (6) recent potential exposure to an infectious agent.

When doing preparticipation physical examinations, it is sometimes assumed that athletes have received all their immunizations. Proof of immunizations is required by schools and colleges, although exceptions can be given to individuals refusing to receive immunizations. In a study surveying 69,115 Minnesota children who entered kindergarten in 1992, by 19 months of age, 73\% of students had received the measles, mumps, and rubella (MMR) vaccine, and only $39 \%$ had received their fourth dose of diphtheria, tetanus, and pertussis vaccine (DTaP) [17]. Vaccination rates can vary substantially by age, race/ethnicity, and neighborhood [17]. White, non-Hispanic students usually have higher vaccination rates than children of other racial/ethnic groups. It has been estimated that $79 \%$ of whites, $76 \%$ of Hispanics, and $71 \%$ of African Americans are fully immunized [18].

\section{Measles, Mumps, and Rubella}

Although MMR vaccines have been administered for many decades and incidences of disease are presently low [7], the diseases can still occur in the adult population. Between 1986 and 1989, 6\% of the measles cases occurred in college

\section{Table 1}

Routine immunizations for adults recommended by the Centers for Disease Control and Prevention, October 2006-September 2007

\begin{tabular}{|c|c|c|c|}
\hline \multirow[b]{2}{*}{ Vaccine } & \multicolumn{3}{|l|}{ Age group (y) } \\
\hline & $19-49$ & $50-64$ & $\geq 65$ \\
\hline $\begin{array}{l}\text { Tetanus, diptheria, pertussis } \\
\text { (Td/DTaP) }\end{array}$ & $\begin{array}{l}\text { 1-dose Td booster } \\
\text { every } 10 \text { y } \\
\text { Substitute } 1 \text { dose of DTaP fo }\end{array}$ & or Td & \\
\hline Human papilloma virus (HPV) & 3 doses (female patients) & & \\
\hline $\begin{array}{l}\text { Measles, mumps, rubella } \\
\text { (MMR) }\end{array}$ & 1 or 2 doses & 1 dose & \\
\hline Varicella & 2 doses $(0,4-8 w k)$ & 2 doses $(0,4-8 w k)$ & \\
\hline Influenza & 1 dose annually & 1 dose annually & \\
\hline $\begin{array}{l}\text { Pneumococcal } \\
\text { (polysaccharide) }\end{array}$ & $1-2$ doses & & 1 dose \\
\hline Hepatitis A & $\begin{array}{l}2 \text { doses }(0,6-12 \mathrm{mo} \\
\text { or } 0,6-18 \mathrm{mo})\end{array}$ & & \\
\hline Hepatitis B & 3 doses $(0,1-2,4-6 \mathrm{mo})$ & & \\
\hline Meningococcal & 1 or more doses & & \\
\hline
\end{tabular}

Data from United States Department of Health and Human Services, Centers for Disease Control and Prevention. Recommended adult immunization schedule, by vaccine and age group. Available at http://www.cdc.gov/ vaccines/recs/schedules/downloads/adult/06-07/adult-schedule-1 1x17. pdf; Accessed November 30, 2006. 
Table 2

Catch-up immunization schedule for children aged 7 through 18 years recommended by the Centers for Disease Control and Prevention

\begin{tabular}{|c|c|c|c|}
\hline \multirow[b]{2}{*}{ Vaccine } & \multicolumn{3}{|c|}{ Minimum interval between doses } \\
\hline & Dose 1 to dose 2 & Dose 2 to dose 3 & Dose 3 to booster dose \\
\hline $\begin{array}{l}\text { Tetanus, diptheria } \\
(T d)^{h}\end{array}$ & 4 wk & $6 \mathrm{mo}$ & $\begin{array}{l}6 \text { mo if first dose given } \\
\text { at age }<12 \text { mo and } \\
\text { current age }<11 \mathrm{y}, \\
\text { otherwise } 5 \mathrm{y}\end{array}$ \\
\hline $\begin{array}{l}\text { Inactivated poliovirus } \\
\qquad(I P V)^{b, i}\end{array}$ & 4 wk & 4 wk & $\mathrm{IPV}^{\mathrm{b}, \mathrm{i}}$ \\
\hline Hepatitis B $(\mathrm{HepB})^{c}$ & 4 wk & $\begin{array}{l}8 \text { wk (and } 16 \text { wk } \\
\text { after first dose) }\end{array}$ & \\
\hline $\begin{array}{l}\text { Measles, mumps, } \\
\text { rubella (MMR) }\end{array}$ & 4 wk & & \\
\hline Varicellai & 4 wk & & \\
\hline
\end{tabular}

aDTaP. The fifth dose is not necessary if the fourth dose was administered after the fourth birthday.

bIPV. For children who received an all-IPV or all-oral poliovirus (OPV) series, a fourth dose is not necessary if a third was administered at age $\geq 4$ years. If OPV and IPV were administered as part of a series, then a total of four doses should be given, regardless of the child's current age.

${ }^{c} \mathrm{HepB}$. Administer the three-dose series to all children and adolescents $<19$ years of age if they were not previously vaccinated.

${ }^{d} M M R$. The second dose of MMR is recommended routinely at age 4 to 6 years but may be administered earlier if desired.

eHib. Vaccine is not generally recommended for children aged $\geq 5$ years.

f $\mathrm{Hib}$. If current age $<12$ months and the first 2 doses were Haemophilus b conjugate vaccine (PRP-OMP) (pedvaxHIB or ComVax [Merck]), then the third (and final) dose should be administered at age 12 to 15 months and at least 8 weeks after the second dose.

SPCV. Vaccine is not generally recommended for children aged $\geq 5$ years.

${ }^{\mathrm{h}} \mathrm{Td}$. Adoloscent tetanus, diptheria, and pertussis vaccine (DTaP) may be substituted for any dose in a primary catch-up series or as a booster if age appropriate for DTaP. A 5-year interval from the last Td dose is encouraged when DTaP is used as a booster dose. See ACIP recommendations for further information.

IIPV. Vaccine is not generally recommended for persons aged $\geq 18$ years.

iVaricella. Administer the two-dose series to all susceptible adolescents aged $\geq 13$ years.

Data from United States Department of Health and Human Services, Centers for Disease Control and Prevention. 2007 Child \& Adolescent Immunization Schedules. Available at http://www.cdc.gov/vaccines/ recs/schedules/downloads/child/2007/child-schedule-color-print.pdf; Accessed November 30, 2006.

students [19]. Enzyme-linked immunosorbent assay tests for antibodies to MMR are available to detect for immunization status [19]. In a series of 256 students, 53 $(21 \%)$ were found to be seronegative to measles alone, $13(5 \%)$ were seronegative to rubella alone, and $5(2 \%)$ were seronegative to measles and rubella. Eighty-six percent of the individuals seronegative to measles had previously received a dose of measles vaccine. Following a second injection, conversion to seropositive status rose to $97 \%$ and $100 \%$ for measles and rubella, respectively. These data support the need for a two-dose vaccine schedule [19].

\section{Pneumococcal Vaccine}

Pneumococcal vaccine is administered to prevent Streptococcus pneumoniae infections. A conjugate heptavalent is given to during the first 2 years of life. A polysaccharide vaccine is provided to high-risk individuals older than 2 years 
against 23 types of Streptococcus pneumonia that account for 90\% of invasive disease [20]. High-risk groups include patients who have asplenia, sickle cell disease, diabetes mellitus, cirrhosis, immunocompromised states, chronic cardiac or pulmonary disease, or age 65 years or older. Immunity following vaccination is successful for periods of 5 to 10 years, requiring booster injections [20].

\section{Hepatitis B}

Hepatitis B is a blood-borne virus transmitted through sexual contact and parenteral exposure to blood and blood components [14]. Hepatitis B has a greater risk for transmission in sports than HIV. The risk of HIV transmission is estimated to between 1 in 1 million games and 1 in 85 million games [14,21]. The risk arises if bleeding and skin exudates from an infected individual come into contact with open wounds in another athlete, particularly during contact and collision sports. There are no confirmed cases of spread of HIV through sports [14]; however, 5 out of 10 high school sumo wrestlers at one club developed hepatitis B [22]. Another case series reported on 11 of 65 American football players who developed hepatitis B over a period of 19 months [23]. Contact through open wounds, cuts, and abrasions were the suspected routes of transmission.

\section{Primary prevention}

Although hepatitis A is a considered immunization in athletes who are traveling to endemic areas, routine vaccination for hepatitis B is recommended for all individuals after birth using single or combination vaccines [24]. A three-dose immunization schedule is typically used after 18 years of age, with injections at 0 months, 1 month, and 6 months, although there is an optional four-dose schedule [25]. The licensed vaccines have had $90 \%$ to $95 \%$ efficacy of preventing hepatitis B, with immunity lasting 15 years or longer [25]. Immunizations for hepatitis B should be checked during the preparticipation physical examination, and catch-up immunizations recommended to the individual (see Table 2). If individuals are uncertain about their immunization status, serologic testing for antibody to hepatitis B surface antigen can determine immunity.

\section{Secondary prevention}

When athletes are known to be infected with hepatitis $\mathrm{B}$, secondary prevention includes education on personal hygiene, appropriate management of open wounds, proper use of protective equipment, safe sex practices using a condom, and avoidance of intravenous blood transmission (eg, through needle sharing and illicit drug use).

\section{Pertussis, Tetanus, and Polio}

Bordetella pertussis, which is responsible for whooping cough, is a gram-negative coccobacillus transmitted by way of airborne droplets [26]. Although tetanus and polio have been controlled well with the use of vaccines [7], the rate of pertussis cases has been increasing in adolescents and adults despite routine immunizations [27]. Most cases occur in patients 10 years or older [28]. 
The infection is most concerning for infants because immunity is not complete until older ages. The spread to infants is typically from adults. Pertussis usually presents with nonspecific upper respiratory tract infection symptoms for 1 to 2 weeks (catarrhal stage), after which the paroxysmal and sometimes uncontrollable cough develops [26]. The cough is not necessarily always followed by the classic "whooping" sound, and pertussis should be considered with any persistent, prolonged cough.

\section{Primary prevention}

The whole-cell pertussis vaccine is estimated to be approximately $85 \%$ effective [29]. This vaccine is still recommended for use in the routine immunization of young children; however, the immunity provided begins to decline at 4 to 12 years following vaccination, which makes adolescents and adults susceptible [27]. Rare adverse reactions from the vaccine include hypotonic, hyporesponsive episodes, high fever, seizures, and anaphylaxis [26]. Two acellular vaccines have been introduced that are as effective as whole-cell vaccines and have fewer adverse reactions [30]. These vaccines are combined with tetanus toxoid and reduced diphtheria toxoid (DTaP). The Centers for Disease Control and Prevention (CDC) recommends use of these DTaP boosters rather than the tetanus-diptheria (Td) booster starting after 11 to 12 years of age [31].

\section{Secondary prevention}

For pertussis, individuals are most contagious during the first 1 to 2 weeks during the catarrhal stage but should be considered contagious until 3 weeks after the paroxysmal stage ends or after taking antibiotics for 5 days [32]. Diagnosis of pertussis infection is best performed through polymerase chain reaction assay (sensitivity, 94\%; specificity, 97\%) or through direct fluorescent antibody testing (sensitivity, 52\%; specificity, 98\%). Nasal swab cultures (sensitivity, $15 \%$; specificity, 100\%) are routinely performed; however, they have high false negative rates and take 7 to 12 days to yield results [33]. Physicians in the United States are legally required to report cases of pertussis to state public health departments [26]. It is estimated that $80 \%$ of susceptible household contacts will be infected after close contact [26]. Antibiotic prophylaxis is recommended for close contacts of persons who have pertussis to prevent outbreaks [34]. Preferred drugs are azithromycin for 5 days, clarithromycin for 7 days, or trimethoprim-sulfamethoxazole or erythromycin for 14 days, which are similar for prophylaxis and treatment [34].

\section{Influenza}

Influenza presents with constitutional symptoms of fever, chills, malaise, fatigue, and myalgia in addition to upper respiratory tract symptoms of a sore throat, cough, and rhinitis. Rarely, more serious conditions can occur, including encephalopathy, transverse myelitis, myocarditis, and pericarditis [9]. Immunogenicity is determined by hemaglutinins and neuraminidases on the virus surface. Antigenic drift can occur that can mutate the virus into different 
strains. Transmission occurs by way of respiratory droplets. The virus has an incubation period of usually 2 days (range, 1-4 days), and adults are infectious from the day before symptoms begin to approximately 5 days after the illness starts [9]. Symptoms usually last a week, although less likely, symptoms can last longer than 2 weeks. These symptoms can be very disruptive for treatment and challenging for the athlete to keep training and competing. A case series of 81 students, mostly healthy adolescents at a ski school in Austria, reported a severe outbreak of influenza A, leading to an attack rate of $49 \%$, with $69 \%$ becoming ill within 2 days of the outbreak. Two students were hospitalized with pneumonia and 1 died [35].

\section{Primary prevention}

Influenza vaccines contain strains of antigenically equivalent strains of influenza similar to those annually recommended: influenza A (H3N2), influenza A ( $\mathrm{H} 1 \mathrm{~N} 1)$, and a B virus. Depending on the emergence and spread of new strains, other virus strains can be added to update the vaccine [9]. The efficacy of influenza vaccine is approximately $70 \%$ to $90 \%$ for individuals under age 65 years [36]. Vaccination for influenza should occur in the fall (October or November), at the beginning of the flu season (Box 2) [9]. Antibodies develop approximately 2 weeks after vaccination $[9,37]$.

Inactivated influenza vaccine is generally appropriate for all populations requiring influenza vaccine. Three influenza vaccines were available in the United States for the 2006 to 2007 season: Fluzone (manufactured by SanofiPasteur); Fluvirin (manufactured by Novartis); and Fluarix (manufactured by GlaxoSmithKline). The typical dose is $0.5 \mathrm{~mL}$ administered intramuscularly, usually in the deltoid muscle. Live, attenuated influenza vaccine (LAIV) is approved for use in healthy, nonpregnant individuals aged 5 to 49

\section{Box 2: Indications for influenza vaccine}

1. Adults and children with chronic disorders of the cardiorespiratory system, including asthma

2. Adults and children who have chronic disease which may require regular medical follow-up or hospitalization, including immunodeficiency

3. Young children aged $6-23$ months

4. Children aged 6 months to 18 years on long-term aspirin therapy and at risk for Reye's syndrome

5. Persons aged $>65$ years

6. Residents of nursing homes or chronic-care facilities

7. Health care workers

8. Travelers to influenza-endemic areas

Adapted from Smith NM, Bresee JS, Shay DK, et al. Prevention and control of influenza: recommendations of the Advisory Committee on Immunization Practices (ACIP). MMWR Recomm Rep 2006;55(RR-10): 1-42. 
years. The LAIV is administered by way of a nasal spray once in each nostril (FluMist, manufactured by MedImmune). Individuals who have a hypersensitivity or anaphylactic reaction to components of the flu vaccine or to eggs should not be vaccinated [9].

Adults reported having a 19\% reduction in severe febrile illnesses after LAIV compared with placebo [38]. Side effects from LAIV increased in adults within 7 days of immunization compared with placebo and consisted mainly of nasal congestion (44.5\% versus $27.1 \%)$ and sore throat $(27.8 \%$ versus $17.1 \%)$, which lasted, on average, 2 days. Less common complaints were tiredness, cough, and chills. There was no significant difference in the number of mild febrile illnesses between immunization and placebo groups [39]. Injections can be scheduled to occur at the optimum time during the athlete's competitive schedule to minimize concern about side effects.

When inactivated influenza vaccine shortages occurred in previous years, the vaccine was recommended for high-risk groups as priority; however, the general recommendation now is to offer the immunization annually to anyone who wishes to reduce the likelihood of being ill with influenza or transmitting the virus if they should become infected [9]. Although this policy cannot be directly translated into a benefit for the athlete, depending on the level of athlete, the use of the LAIV may also be beneficial to prevent lost time from sport. Influenza vaccine has been suggested for competitive athletes and essential personnel, especially before international events occurring during the influenza season $[4,40]$.

\section{Secondary prevention}

Treatment with antiviral medications can reduce the duration of uncomplicated influenza A and B illness by approximately 1 day when administered within 2 days of illness onset [41,42]. Recommended antiviral treatment should be given for 5 days [9]. Four antiviral agents are currently available: amantadine, rimantadine, zanamivir, and oseltamivir [9]. The influenza A virus, however, has become resistant to amantadine and rimantadine, which are presently not recommended to be used as first-line drugs [43]. Zanamivir (Ralenza, dry powder taken by orally inhaled route) and oseltamivir (Tamiflu, capsule or oral suspension) are neuraminidase inhibitors and can be used to treat patients and to control influenza outbreaks in closed settings. Although typically used in nursing homes, an outbreak in a dormitory may require chemoprophylaxis [9]. There are limited data to suggest that serious complications from influenza, such as lower respiratory tract infections, may be reduced [44]. The use of antiviral medications for prophylaxis of influenza is unclear and is not yet recommended for routine seasonal control [45]. The use of oseltamivir, however, has been recommended in specific cases, especially if there is high risk of spread such as household contacts and if individuals have not been immunized [46]. Oseltamivir was used to treat 36 of 188 patients, including 13 athletes during the 2002 Salt Lake City Winter Olympics, with medications given to close contacts, which was believed to limit the spread of influenza [47]. 
Clinical history and physical examination are still the mainstays for diagnosing influenza. Rapid swab tests are available and take approximately 30 minutes to detect the influenza virus. The tests are less sensitive (72\%-95\%) and specific $(76 \%-86 \%)$ than the traditional viral cultures [48]. They have moderate sensitivities for influenza antigens and are more likely to produce false negative rather than false positive results [48,49]. Direct and indirect fluorescent antibody staining tests are also available, but they are ordered more in hospitals because they take 2 to 4 hours to obtain results [49]. Viral cultures are still the "gold standard" for confirming the presence of influenza and identifying the strains and subtypes [9].

\section{Meningitis}

Neisseria meningitides is a serious concern, especially for the adolescent and college populations. An alarming trend during the 1970s demonstrated an increase in meningitis deaths in college students, with living in dormitories being a risk factor. The disease can be spread by asymptomatic carriers. Students living in dormitories were 9 to 23 times more likely of getting infected than those living in other types of accommodations [50]. Freshmen who lived in dormitories had an elevated risk of meningococcal disease (odds ratio, 3.6; 95\% confidence interval, $1.6-8.5 ; P=.003)$ compared with other college students [51]. Aside from the risk of death, $11 \%$ to $19 \%$ of survivors of meningitis have serious sequelae such as neurologic disability, limb loss, and hearing loss [50].

\section{Primary prevention}

Routine vaccination with meningococcal vaccine is recommended for college freshmen living in dormitories and for other populations at increased risk. The CDC Advisory Committee on Immunization Practices recommends routine vaccination of young adolescents (11-12 years old) with meningococcal vaccine (MCV4) at the preadolescent health care visit [50]. Therefore, sports medicine physicians may be faced with higher frequency of checking for meningococcal immunization status for high school and college athletes. A tetravalent conjugate vaccine (Menactra, Sanofi Pasteur) is available against Neisseria meningitidis isolates $\mathrm{A}, \mathrm{C}, \mathrm{Y}$, and $\mathrm{W}-135$ in a $0.5-\mathrm{mL}$ single-dose vial. Over the age of 11 years, $75 \%$ of the meningococcal infections are caused by strains C, Y, or W-135 (CDC, unpublished data, 2004) [50]. Another vaccine, Menomune (Aventis Pasteur Limited), has been licensed since 1981 and has a similar immunogenicity profile to Menactra and is delivered subcutaneously as a 0.5 $\mathrm{mL}$ dose. Menactra and Menomune have serum bactericidal protection ranging from $89.4 \%$ and $94.4 \%$ for strain W-135 and 73.5\% and 79.4\% for strain Y, respectively [50]. Revaccination may be necessary for individuals at high risk after 5 years $[52,53]$. Common side effects with MCV4 were local pain in just over 50\% of patients, followed by swelling, induration, and redness in approximately $10.8 \%$ to $17.1 \%$. Fever was reported in $5.1 \%$ of children 18 years old or younger and in $1.5 \%$ of adults [50]. 


\section{Secondary prevention}

Close contacts are at high risk and should be treated with chemoprophylaxis ideally within 24 hours of identifying the index patient [50]. The goal of treatment is to reduce nasopharyngeal carriage of $\mathcal{N}$ meningitidis. After more than 14 days after the onset of illness in the index patient, chemoprophylaxis is not necessary [50]. A single dose of ciprofloxacin (500 mg orally) or ceftriaxone $(250 \mathrm{mg}$ by intramuscular injection), or rifampin (600 $\mathrm{mg}$ twice a day for 2 days) is recommended for adults. Children between 1 month and 18 years old may take rifampin (10 $\mathrm{mg} / \mathrm{kg}$ every 12 hours for 2 days), or ceftriaxone (125 mg intramuscularly) if younger than 15 years [50]. One dose of azithromycin $(500 \mathrm{mg})$ was also shown to eradicate $\mathcal{N}$ meningitidis and may represent another treatment option [54].

\section{Human Papillomavirus}

Human papillomavirus (HPV) is associated with 99\% of cervical cancers and anogenital, head and neck, and nonmelanoma skin cancers. It is an STD and can be diagnosed by abnormal cervical cell changes seen on Pap smear [55]. This is a common infection, especially in sexually active adolescents and university students [56].

\section{Primary prevention}

Primary prevention is now possible with two new vaccines: a bivalent vaccine against HPV types 16 and 18 and a quadravalent vaccine against types 6,11 , 16 , and 18 . The vaccines have a three-dose schedule: 0,1 , and 6 months (bivalent vaccine) and 0,2 , and 6 months (quadravalent vaccine). At 4.5 years, the bivalent vaccine was effective for producing a persistent antibody response against HPV 16 and 18, with more than 98\% seropositivity and $96.9 \%$ effectiveness (95\% confidence interval, 81.3-99.9) in reducing the number of reported abnormalities on Pap smear, colposcopy, or both [57]. Routine vaccination with three doses of quadrivalent HPV vaccine is recommended for girls 11 to 12 years old but can be started in girls as young as 9 years. Girls and women aged 13 to 26 years who have not been vaccinated previously or who have not completed the full vaccine series are recommended to receive a catch-up series. The vaccine is intended to be administered before potential exposure to HPV through sexual contact [58].

\section{Secondary prevention}

Secondary prevention involves checking the affected individual's partners for signs of genital warts and other STDs. Regular cervical screen is recommended. Use of condoms and education on spread is important. HPV infection persists for life; however, the degree and duration of contagiousness is yet unknown [59].

\section{Travel Immunizations}

Athletes traveling need to consider the endemic diseases in the geographic location where they are competing. They should be aware of risks of acquiring common diseases, their accommodations (urban versus rural), local foods, and 
customs. Immunizations should ideally be planned 4 or more months in advance to allow for adequate time to administer vaccines (Table 3 ). There are many resources for information about prevention of infectious diseases for travelers (Table 4).

\section{Table 3}

\section{Recommended immunizations for travelers to developing countries ${ }^{a}$}

\begin{tabular}{|c|c|c|c|}
\hline \multirow[b]{2}{*}{ Immunizations } & \multicolumn{3}{|c|}{ Length of travel } \\
\hline & $\begin{array}{l}\text { Brief, } \\
<2 w k\end{array}$ & $\begin{array}{l}\text { Intermediate, } \\
2 \text { wk to } 3 \mathrm{mo}\end{array}$ & $\begin{array}{l}\text { Long-term } \\
\text { residential, >3 mo }\end{array}$ \\
\hline $\begin{array}{l}\text { Review and complete } \\
\text { age-appropriate } \\
\text { childhood schedule (see } \\
\text { text for details) } \\
\text { DTaP, poliovirus, } \\
\text { pneumococcal, and } \\
\text { Haemophilus influenzae } \\
\text { type b vaccines may be } \\
\text { given at } 4 \text {-wk intervals if } \\
\text { necessary to complete the } \\
\text { recommended schedule } \\
\text { before departure } \\
\text { Measles: } 2 \text { additional } \\
\text { doses given if younger } \\
\text { than } 12 \text { mo of age } \\
\text { at first dose } \\
\text { Varicella } \\
\text { Hepatitis } \mathrm{B}^{\mathrm{b}}\end{array}$ & + & + & + \\
\hline Yellow fever ${ }^{c}$ & + & + & + \\
\hline Hepatitis $A^{d}$ & + & + & + \\
\hline Typhoid fever ${ }^{\mathrm{e}}$ & \pm & + & + \\
\hline Meningococcal disease ${ }^{f}$ & \pm & \pm & \pm \\
\hline Rabies $^{9}$ & \pm & + & + \\
\hline Japanese encephalitis ${ }^{h}$ & \pm & \pm & + \\
\hline
\end{tabular}

$+=$ recommended; $\pm=$ consider.

aSee disease-specific chapters in Section 3 of the AAP Red Book for details: [Red Book: 2006 report of the Committee of Infectious Diseases. 27th edition. Elk Grove Village, (IL) American Academy of Pediatrics; 2006]. For further sources of information, see text.

bIf insufficient time to complete 6-month primary series, accelerated series can be given (see text for details).

cFor regions with endemic infection.

Indicated for travelers to areas with intermediate or high endemic rates of HAV infection.

endicated for travelers who will consume food and liquids in areas of poor sanitation.

fRecommended for regions of Africa with endemic infection and during local epidemics, and required for travel to Saudi Arabia for the Haji.

Indicated for people with high risk of animal exposure (especially to dogs) and for travelers to countries with endemic infection.

${ }^{h}$ For regions with endemic infection. For high-risk activities in areas experiencing outbreaks, vaccine is recommended, even for brief travel.

From American Academy of Pediatrics. International travel. In: Pickering LK, editor. Red book: 2006 report of the committee on infectious diseases. 27th edition. Elk Grove Village (IL): American Academy of Pediatrics; 2006. p. 99; with permission from the American Academy of Pediatrics. 


\begin{tabular}{|c|c|c|}
\hline \multicolumn{3}{|c|}{$\begin{array}{l}\text { Table } 4 \\
\text { More common tick-borne diseases }\end{array}$} \\
\hline Tick-borne disease & Organism & $\begin{array}{l}\text { Common vector (geographic } \\
\text { area) }\end{array}$ \\
\hline Rocky Mountain spotted fever & Rickettsia rickettsii & $\begin{array}{l}\text { Dog tick, Dermacentor variabilis } \\
\text { (central, Pacific coastal, and } \\
\text { eastern US) } \\
\text { Rocky Mountain wood tick, } \\
\text { Dermacentor andersoni } \\
\text { (western US) }\end{array}$ \\
\hline $\begin{array}{l}\text { Human monocytotropic } \\
\text { ehrlichiosis }\end{array}$ & Ehrlichia chaffeensis & $\begin{array}{l}\text { Lone Star tick (south central US in } \\
\text { Maryland, Arkansas, } \\
\text { Tennessee, Oklahoma, and } \\
\text { Missouri) [60] }\end{array}$ \\
\hline $\begin{array}{l}\text { Human granulocytotropic } \\
\text { anaplasmosis }\end{array}$ & $\begin{array}{l}\text { Anaplasma } \\
\text { phagocytophilum }\end{array}$ & $\begin{array}{l}\text { Blacklegged tick, Ixodes } \\
\text { scapularis (north central US } \\
\text { and New England) } \\
\text { Ixodes pacificus (California) [75] }\end{array}$ \\
\hline Lyme disease & Borrelia burgdorferi & $\begin{array}{l}\text { Ixodes scapularis (eastern US in } \\
\text { New England and mid-Atlantic } \\
\text { states and Midwest US in } \\
\text { Wisconsin and Minnesota) } \\
\text { lxodes pacificus (west in northern } \\
\text { California) }\end{array}$ \\
\hline Babesiosis & $\begin{array}{l}\text { Parasite, Babesia } \\
\text { microti }\end{array}$ & $\begin{array}{l}\text { Ixodes scapularis (northeast of } \\
\text { the US) }\end{array}$ \\
\hline
\end{tabular}

Abbreviation: US, United States.

\section{BUG-BORNE DISEASE PREVENTION}

Mosquito-Borne Disease

A number of arthropods, such as mosquitoes and ticks, can transmit diseases. Mosquito-vector diseases include West Nile virus, yellow fever virus, and dengue virus. West Nile virus, a flavivirus, has demonstrated a seasonally endemic epidemiology with geographic variation in the United States, especially in California, Arizona, and Colorado [7,61]. This disease typically presents between July and October, although cases have presented between April and December. The prevention of mosquito bites is the cornerstone of prevention. An athlete in an endemic area should wear an insect repellant such as deet $(\mathcal{N}, \mathcal{N}$-diethyl-mtoluamide), picaridin (KBR-3023), or oil of lemon eucalyptus ( $p$-menthane-3,8 diol). Deet and permethin may be applied to the clothing [62]. If a sunscreen is used concomitantly, the insect repellant should be applied on top of this and removed at the end of the day. Long-sleeved shirts that are tucked into long pants are also useful.

\section{Tick-Borne Disease}

Tick-borne diseases include rickettsial diseases, Lyme disease, babesiosis, tickborne relapsing fever, and occasionally, tularemia and $\mathrm{Q}$ fever (Table 5). 


\section{Table 5}

Suggested resources for preventing infections

Topic

Web site

Vaccines licensed for immunization and distribution in the United States

How to store and handle vaccines

Adult immunization schedule

Travel information

Children and adolescents immunization schedule

HIV position statements

Morbidity and Mortality Weekly Reports

Primer for physicians for preventing food-borne illnesses www.fda.gov/cber/vaccine/licvacc.htm

http://www.vaccineinformation.org/ www.cdc.gov/nip/menus/ vaccines.htm\#Storage http://www.cdc.gov/nip/recs/ adult-schedule.htm www.cdc.gov/travel www.who.int/ith http://www.cdc.gov/nip/recs/ child-schedule.htm http://www.fims.org/ (International Federation of Sports Medicine) http://www.casm-acms.org/forms/ statements/HIVEng.pdf (Canadian Academy of Sport Medicine) http://www.amssm.org/hiv.html (American Medical Society for Sports Medicine and the American Orthopaedic Society for Sports Medicine) www.cdc.gov/mmwr http://www.cdc.gov/mmwr/preview/ $\mathrm{mmwrhtml} / \mathrm{rr} 5002 \mathrm{al} . \mathrm{htm}$

Web sites accessed November 3, 2006.

Certain athletes who participate in rural outdoor activities are more susceptible to tick bites. These sports include cross-country running, training in multiple sports in rural areas, and recreational outdoor sports such as fishing and hiking. Children are more at risk to tick bites.

Three more common rickettsial illnesses are Rocky Mountain spotted fever, human monocytotropic ehrlichiosis, and human granulocytotropic anaplasmosis [60]. The infectious organisms responsible for these illnesses maintain their lifecycles in mammals and ticks. Their prevalence reflects the geographic locations and the seasonality of the tick abundance. Their season is usually from April to September, but they can present throughout the year. Newer rickettsial diseases are emerging. These potentially lethal diseases are difficult to diagnose because they often mimic viral syndromes. As many as $60 \%$ to $75 \%$ of patients are initially misdiagnosed $[63,64]$.

With Rocky Mountain spotted fever, more than $50 \%$ of cases are reported in the five states of North Carolina, South Carolina, Tennessee, Oklahoma, and Arkansas [65]. The presentation most often manifests as a sudden febrile illness with headache, myalgia, and a maculopapular rash that spreads in a centripetal pattern. Rickettsia rickettsii has a predilection for endothelial cells and can cause 
a diffuse vasculitis and an untreated mortality of 10\%. The diagnosis is based on clinical presentation, with epidemiologic, geographic, and seasonal considerations. Laboratory testing may be supportive with thrombocytopenia and mild liver enzyme elevation. Serologic testing is supportive only on a delayed basis with acute and convalescent titers. Human monocytotropic ehrlichiosis and human granulocytotropic anaplasmosis can also present with acute headache, fever, and myalgia. Laboratory evaluation often demonstrates leukopenia, thrombocytopenia, and transaminase elevation.

Common tick-borne illnesses that have been reported in the northeast United States are Lyme disease and babesiosis, which are transmitted by the tick Ixodes scapularis [66]. Babesiosis can cause a febrile illness and possibly life-threatening anemia and thrombocytopenia. Lyme disease is a rickettsial disease caused by Borrelia burgdorferi. As such, concurrent disease may be caused by the same tick bite (see Table 4).

\section{Tick-bite prevention}

There are no proven vaccines for these tick-borne illnesses, but all are preventable by careful vigilance and protection. The key to prevention is to understand the regional epidemiology and seasonality of the diseases. Vaccination for Lyme disease (LYMErix) was originally approved; however, the manufacturer took the vaccine off the market due to declining sales. There was a $49 \%$ efficacy after two doses and a 76\% efficacy after three doses [67]; however, the protection diminished after 2 years.

Ticks thrive in a wooded environment and at the edge of woods with surrounding high vegetation. Ticks are uncommon in well-mowed lawns. Relative tick-free zones can be created by placing wood chips or gravel around recreational areas to separate the woods [68]. Other landscape management tips include removing clippings and leaves, keeping stone walls clean of leaves, and restricting the use of groundcover, such as pachysandra, where pets and children may play. Widening woodland trails andkeeping in the center of the trail while walking may be helpful. When traveling in wooded areas, light-colored clothing is helpful to identify the tick. Long pants tucked into tightly woven socks and closed shoes minimize exposure. Deet at 10\% to 25\% should be applied to the skin. Permethrin may be applied only to the clothing. Clothes should be removed and cleaned and dried after exposure. The clothes dryer is effective in killing ticks. One should carefully check for ticks in the nymphal phase that may be the size of a pin head. Careful inspection should be done of the hair, ears, axilla, belly button, and legs. Children and pets should also be checked. It is also important to monitor pets that may travel in the woods and return indoors.

The technique of tick removal is critical. Tweezers with fine tips should be used close to the skin and pulled directly away. Squeezing the body may allow contamination of the disease into the host [69]. Lyme disease is not contracted until at least 24 hours of tick adherence [70]; however, ehrlichiosis may transmit in less than 24 hours. Preventive antibiotics are generally not indicated 
because less than 5\% of bites are Lyme infected, especially with a flat tick. After a high-risk exposure (when the tick has been engaged for more than 24 hours and is engorged), a single dose of $200 \mathrm{mg}$ of doxycycline is believed to be effective [71].

\section{HYGIENE PRECAUTIONS AND INFECTION CONTROL}

Personal Hygiene

Most infectious diseases are spread from contact with the microorganism directly or indirectly from the infected individual. Athletes frequently interact with teammates, coaches, athletic trainers, and physicians and share equipment, water bottles, towels, and supplies. This interaction is particularly a concern, with the recent outbreaks of methicillin-resistent Staphylococcus aureus (MRSA) infections among sports teams [72,73]. Three categories of potential risk factors for spreading infection have been suggested: "sharing" (sharing soap/towels/water bottles with teammates), "skin injury" (cuts, abrasions), and "close contact" (locker adjacent to infected teammate, living on-campus) [74].

Good personal hygiene can help reduce colonization of bacteria. Bacterial counts can range from 5000 to 5 million colony-forming units per square centimeter on the hands [75]. Universal body fluid precautions-for example, using disposable gloves when examining the oral cavity or wounds and frequent hand washing-can reduce the risk of infection. MRSA is transmitted from an infected patient to the gloves of a health care worker in approximately 17\% (9\%-25\%). Physicians, in particular, have a low compliance for using gloves and washing their hands [76]. Proper surgical hand washing is recommended to be 15 to 30 seconds with soap, a 30 -second rinse with water, followed by complete drying with a towel. The use of rinses and gels with concentrations of 50\% to $95 \%$ alcohol take 15 seconds to use and are effective at killing organisms [75]. The use of chlorhexidine soap has been useful for reducing MRSA infections.

Viruses and bacteria can exist on equipment. MRSA was found in the taping gel and whirlpool in the training facilities of a professional football team [72]. Using diluted bleach (1 part bleach in 9 parts water) to cleanse training areas and equipment is recommended [8]. Routine cleaning schedules for shared equipment should be established and recorded.

For upper respiratory tract infections, isolation of those who have had close contact with someone who has a confirmed or suspected infection, especially those who have active symptoms such as persistent fever and cough, is an effective and practical method of avoiding contact [8].

Any athlete who has a scratch, abrasion, or laceration or who has potentially infectious skin lesions such as vesicular or weeping skin lesions should be removed from play until the area can be securely covered with occlusive bandages or dressings to prevent leakage of blood or serous fluid [77]. Uniforms with fresh blood should be removed and replaced immediately after stopping any bleeding. Bleach diluted with tap water in a 1:10 ratio can be used to wash equipment that has had contact with blood or body fluid. Body substance 
precautions should be taken by health care professionals at all times when treating open wounds.

\section{Prevention of Methicillin-Resistant Staphylococcus Aureus}

One type of bacteria that has become more common in the hospital and a community-acquired infection is MRSA. Although contact sports such as wrestling and football have been commonly associated with MRSA spread, this infection has also been discovered in minimal-contact sports such as fencing [78]. Three factors are associated with MRSA spread in sports. First, even with sports that have minimal contact, there are often abrasions and chaffing from clothing and hot environments. Second, equipment is often shared and there is potential for transmission of bacteria. Third, many sports have sufficient skin-to-skin contact to transmit organisms. Subsequently, health care providers should strongly encourage good overall and hand hygiene in addition to covering all wounds and limiting shared equipment. It is crucial to have an ample supply of soap and water and alcohol-based hand cleansers. Athletes, staff, and coaches should be educated in proper first aid for wounds, in recognition of wounds that are potentially infected, and in seeking medical attention for lesions that have concerning signs, especially large pustules or boils.

\section{Prevention of Fungal Rashes}

Athlete's foot, tinea pedis, is a common ailment not only during the hot summer months but also during the winter months with indoor sports. A number of prevention items include washing feet daily; drying between the toes; wearing cotton, nonsynthetic socks; wearing bathing shoes in public showers; and wearing sandals in warmer weather. Jock itch, tinea cruris, is best prevented by showering immediately after athletic endeavors and wearing cotton briefs. A good talc powder may be used for prevention of athlete's foot and jock itch. Ring worm, tinea corporis, is best prevented by avoiding contact. Contact athletes such as wrestlers should not participate until any lesions have cleared or can be safely and effectively covered.

\section{SEXUALLY TRANSMITTED DISEASE PREVENTION}

Athletes may manifest risk-taking behavior and subsequently be at increased risk for STDs [2]. The preparticipation examination affords the opportunity for the clinician to address these concerns. The CDC has emphasized the five intervention strategies [79], which include education on sexual behavior, identification of asymptomatic individuals, diagnosis and treatment of infected individuals, counseling of sexual partners of persons who have an STD, and pre-exposure vaccination when applicable. Individuals at risk should be questioned about partners regarding number and same or opposite sex. Information about the type of sexual activity, the use of protection, and history of previous STDs should also be identified.

Preventive measures for an STD include abstinence if an individual or partner is actively infected and undergoing treatment. Pre-exposure prophylaxis is relevant in several situations. Hepatitis B vaccine is recommended in all 
individuals potentially exposed to STDs. Hepatitis A vaccine is recommended for all men who have sex with men or users of illicit drugs (injectable and noninjectable). For girls and women aged 9 to 26 years, the new quadrivalent vaccine for HPV types 6, 11,16, and 18 is recommended due to the higher associated risk of cervical cancer.

Most condoms are made of latex and are quite effective in STD prevention. In one study of partners of HIV-infected individuals, partners were 80\% less likely to seroconvert than those who did not use condoms [80]. The male condom can also reduce the transmission of gonorrhea, chlamydiosis, and trichomiasis [81]. There may be some added protection against herpes simplex virus 2 and a 70\% reduction of HPV transmission $[82,83]$. When an individual is allergic to latex, certain polyurethane condoms are likely just as effective, although they may break more readily. Conversely, natural-membrane condoms such as lambskin are too porous to be used for STD prevention. Only water-based lubricants should be used with latex condoms because oil bases will weaken the latex. The female condom is a double-ringed polyurethane sheath that is used vaginally and during anal receptive intercourse that is effective in limited trials in preventing HIV/STDs $[84,85]$. Spermicides and nonbarrier contraception have no role in STD prevention.

Finally, providers should encourage patients who have STDs to notify their partners. Often, this notification is pursued by the public health department. In the event of exposure to HIV by sexual exposure or needle stick, HIV prophylaxis is often undertaken and should be immediate. Prophylactic treatment usually involves the hospital infectious disease division to determine the best combination therapy.

\section{SUMMARY}

Education is paramount in public health and in the prevention of infectious diseases. Athletes are a high-risk population often due to their increased exposure to different people and environments and, sometimes, their outgoing lifestyle behaviors. Primary prevention can be promoted through accurate immunizations; appropriate, planned health maintenance; good hygiene practices; and behavior modification to minimize high-risk activities. Secondary prevention can be achieved through vigilant surveillance for reportable illnesses, proper education and containment for reducing spread if an illness occurs, and timely prophylaxis with medications and immunizations in certain cases.

\section{References}

[1] Roberts JA, Wilson JA, Clements GB. Virus infections and sports performance-a prospective study. Br J Sports Med 1988;22(4):161-2.

[2] Nattiv A, Puffer JC, Green GA. Lifestyles and health risks of collegiate athletes: a multi-center study. Clin J Sport Med 1997;7(4):262-72.

[3] Ehresmann KR, Hedberg CW, Grimm MB, et al. An outbreak of measles at an international sporting event with airborne transmission in a domed stadium. J Infect Dis 1995;171(3): 679-83.

[4] Tarrant M, Challis EB. Influenza vaccination for athletes? CMAJ 1988;139(4):282. 
[5] Plasencia A, Segura A, Farres J, et al. Pneumococcal vaccine for Olympic athletes and visitors to Spain. Barcelona Olympic Organizing Committee. N Engl J Med 1992;327(6): 437.

[6] Brennan RJ, Keim ME, Sharp TW, et al. Medical and public health services at the 1996 Atlanta Olympic Games: an overview. Med J Aust 1997;167(11-12):595-8.

[7] Jajosky RA, Hall PA, Adams DA, et al. Summary of notifiable diseases-United States, 2004. MMWR Morb Mortal Wkly Rep 2006;53(53):1-79.

[8] So RC, Ko J, Yuan YW, et al. Severe acute respiratory syndrome and sport: facts and fallacies. Sports Med 2004;34(15):1023-33.

[9] Smith NM, Bresee JS, Shay DK, et al. Prevention and control of influenza: recommendations of the Advisory Committee on Immunization Practices (ACIP). MMWR Recomm Rep 2006;55(RR-10): 1-42.

[10] Centers for Disease Control and Prevention. Basic information about SARS. Available at: http://www.cdc.gov/ncidod/SARS/factsheet.htm. Accessed November 3, 2006.

[1 1] Pate RR, Trost SG, Levin S, et al. Sports participation and health-related behaviors among US youth. Arch Pediatr Adolesc Med 2000;154(9):904-1 1.

[12] Sklarek HM, Mantovani RP, Erens E, et al. AIDS in a bodybuilder using anabolic steroids. N Engl J Med 1984;311(26):1701.

[13] Scott M, Scott M Jr. HIV infection associated with injections of anabolic steroids. JAMA 1989;262(2):207-8.

[14] Kordi R, Wallace WA. Blood borne infections in sport: risks of transmission, methods of prevention, and recommendations for hepatitis $\mathrm{B}$ vaccination. $\mathrm{Br} \mathrm{J}$ Sports Med 2004;38(6):678-84 [discussion: 678-84].

[15] Rich JD, Dickinson BP, Feller A, et al. The infectious complications of anabolic-androgenic steroid injection. Int J Sports Med 1999;20(8):563-6.

[16] American Academy of Pediatrics, et al. Active and passive immunization. In: Pickering LK, Baker CJ, Long SS, editors. Red book: 2006 report of the Committee of Infectious Diseases. 27th edition. Elk Grove Village (IL): American Academy of Pediatrics; 2006. p. 1-93.

[17] Ehresmann KR, White KE, Hedberg CW, et al. A statewide survey of immunization rates in Minnesota school age children: implications for targeted assessment and prevention strategies. Pediatr Infect Dis J 1998;17(8):711-6.

[18] Tallia AF, Ibsen KH, Howarth DF. Swanson's family practice review: a problem-oriented approach. 5th edition. Philadelphia: Elsevier Inc.; 2005:468.

[19] Cote TR, Sivertson D, Horan JM, et al. Evaluation of a two-dose measles, mumps, and rubella vaccination schedule in a cohort of college athletes. Public Health Rep 1993;108(4): 431-5.

[20] Mufson MA. Antibody response of pneumococcal vaccine: need for booster dosing? Int J Antimicrob Agents 2000; 14(2):107-12.

[21] Brown LS Jr, Drotman DP, Chu A, et al. Bleeding injuries in professional football: estimating the risk for HIV transmission. Ann Intern Med 1995; 122(4):273-4.

[22] Kashiwagi $S$, Hayashi J, Ikematsu $H$, et al. An outbreak of hepatitis $B$ in members of a high school sumo wrestling club. JAMA 1982;248(2):213-4.

[23] Tobe K, Matsuura K, Ogura T, et al. Horizontal transmission of hepatitis B virus among players of an American football team. Arch Intern Med 2000; 160(16):2541-5.

[24] Mast EE, Margolis HS, Fiore AE, et al. A comprehensive immunization strategy to eliminate transmission of hepatitis $B$ virus infection in the United States: recommendations of the Advisory Committee on Immunization Practices (ACIP) part 1: immunization of infants, children, and adolescents. MMWR Recomm Rep 2005;54(RR-16): 1-31.

[25] American Academy of Pediatrics, et al. Hepatitis B. In: Pickering LK, Baker CJ, Long SS, editors. Red book: 2006 report of the Committee of Infectious Diseases. 27th edition. Elk Grove Village (IL): American Academy of Pediatrics; 2006. p. 169-71.

[26] Gregory DS. Pertussis: a disease affecting all ages. Am Fam Physician 2006;74(3): 420-6. 
[27] Wendelboe AM, Van Rie A, Salmaso $S$, et al. Duration of immunity against pertussis after natural infection or vaccination. Pediatr Infect Dis J 2005;24(Suppl 5):S58-61.

[28] Hopkins RS, Jajosky RA, Hall PA, et al. Summary of notifiable diseases-United States, 2003. MMWR Morb Mortal Wkly Rep 2005;52(54): 1-85.

[29] Olin P, Rasmussen F, Gustafsson L, et al. Randomised controlled trial of two-component, three-component, and five-component acellular pertussis vaccines compared with wholecell pertussis vaccine. Ad Hoc Group for the Study of Pertussis Vaccines. Lancet 1997;350(9091): 1569-77.

[30] Jefferson T, Rudin M, DiPietrantonj C. Systematic review of the effects of pertussis vaccines in children. Vaccine 2003;21(17-18):2003-14.

[31] Broder KR, Cortese MM, Iskander JK, et al. Preventing tetanus, diphtheria, and pertussis among adolescents: use of tetanus toxoid, reduced diphtheria toxoid and acellular pertussis vaccines recommendations of the Advisory Committee on Immunization Practices (ACIP). MMWR Recomm Rep 2006;55(RR-3): 1-34.

[32] American Academy of Pediatrics, et al. Pertussis. In: Pickering LK, Baker CJ, Long SS, editors. Red book: 2006 report of the Committee of Infectious Diseases. 27th edition. Elk Grove Village (IL): American Academy of Pediatrics; 2006. p. 472-86.

[33] Loeffelholz M, Thompson CJ, Long KS, et al. Comparison of PCR, culture, and direct fluorescent-antibody testing for detection of Bordetella pertussis. J Clin Microbiol 1999;37(9): 2872-6.

[34] Tiwari T, Murphy TV, Moran J. Recommended antimicrobial agents for the treatment and postexposure prophylaxis of pertussis: 2005 CDC guidelines. MMWR Recomm Rep 2005;54(RR-14): 1-16.

[35] Lyytikainen $\mathrm{O}$, Hoffmann E, Timm H, et al. Influenza A outbreak among adolescents in a ski hostel. Eur J Clin Microbiol Infect Dis 1998;17(2):128-30.

[36] Wilde JA, McMillan JA, SerwintJ, et al. Effectiveness of influenza vaccine in health care professionals: a randomized trial. JAMA 1999;281(10):908-13.

[37] Brokstad KA, Cox RJ, Olofsson J, et al. Parenteral influenza vaccination induces a rapid systemic and local immune response. J Infect Dis 1995;171(1):198-203.

[38] Belshe RB, Nichol KL, Black SB, et al. Safety, efficacy, and effectiveness of live, attenuated, cold-adapted influenza vaccine in an indicated population aged 5-49 years. Clin Infect Dis 2004;39(7):920-7.

[39] Nichol KL, Mendelman PM, Mallon KP, et al. Effectiveness of live, attenuated intranasal influenza virus vaccine in healthy, working adults: a randomized controlled trial. JAMA 1999;282(2): 137-44.

[40] Ross DS, Swain R, Thomas J. Study indicates influenza vaccine beneficial for college athletes. WV Med J $2001 ; 97(5): 235$.

[41] Matsumoto K, Ogawa N, Nerome K, et al. Safety and efficacy of the neuraminidase inhibitor zanamivir in treating influenza virus infection in adults: results from Japan. GG 167 Group. Antivir Ther 1999;4(2):61-8.

[42] Cooper NJ, Sutton AJ, Abrams KR, et al. Effectiveness of neuraminidase inhibitors in treatment and prevention of influenza $A$ and $B$ : systematic review and meta-analyses of randomised controlled trials. BM 2003;326(7401):1235-43.

[43] BrightRA, Shay DK, Shu B, et al. Adamantane resistance among influenza A viruses isolated early during the 2005-2006 influenza season in the United States. JAMA 2006;295(8): 891-4.

[44] Kaiser L, Wat C, Mills T, et al. Impact of oseltamivir treatment on influenza-related lower respiratory tract complications and hospitalizations. Arch Intern Med 2003;163(14): 1667-72.

[45] Jefferson T, Demicheli $V$, Rivetti $D$, et al. Antivirals for influenza in healthy adults: systematic review. Lancet 2006;367(9507):303-13.

[46] Uhnoo I, Linde A, Pauksens K, et al. Treatment and prevention of influenza: Swedish recommendations. Scand J Infect Dis 2003;35(1):3-11. 
[47] Gundlapalli AV, Rubin MA, Samore MH, et al. Influenza, winter Olympiad, 2002. Emerg Infect Dis 2006; 12(1):144-6.

[48] Rodriguez WJ, Schwartz RH, Thorne MM. Evaluation of diagnostic tests for influenza in a pediatric practice. Pediatr Infect Dis J 2002;21 (3):193-6.

[49] Uyeki TM. Influenza diagnosis and treatment in children: a review of studies on clinically useful tests and antiviral treatment for influenza. Pediatr Infect Dis J 2003;22(2):164-77.

[50] Bilukha OO, Rosenstein N. Prevention and control of meningococcal disease. Recommendations of the Advisory Committee on Immunization Practices (ACIP). MMWR Recomm Rep 2005;54(RR-7): 1-21.

[51] Bruce MG, Rosenstein NE, Capparella JM, et al. Risk factors for meningococcal disease in college students. JAMA 2001;286(6):688-93.

[52] Control and prevention of meningococcal disease: recommendations of the Advisory Committee on Immunization Practices (ACIP). MMWR Recomm Rep 1997;46(RR-5):1-10.

[53] Trotter CL, Andrews NJ, Kaczmarski EB, et al. Effectiveness of meningococcal serogroup C conjugate vaccine 4 years after introduction. Lancet 2004;364(9431):365-7.

[54] Girgis N, Sultan Y, Frenck RW Jr, et al. Azithromycin compared with rifampin for eradication of nasopharyngeal colonization by Neisseria meningitidis. Pediatr Infect Dis J 1998; 17(9): 816-9.

[55] Moscicki AB, Hills N, Shiboski S, et al. Risks for incident human papillomavirus infection and low-grade squamous intraepithelial lesion development in young females. JAMA 2001;285(23):2995-3002.

[56] Winer RL, Lee SK, Hughes JP, et al. Genital human papillomavirus infection: incidence and risk factors in a cohort of female university students. Am J Epidemiol 2003;157(3):218-26.

[57] Harper DM, Franco EL, Wheeler CM, et al. Sustained efficacy up to 4.5 years of a bivalent $L 1$ virus-like particle vaccine against human papillomavirus types 16 and 18: follow-up from a randomised control trial. Lancet 2006;367(9518):1247-55.

[58] CDC. ACIP provisional recommendations for the use of quadrivalent HPV vaccine. Available at: http://www.cdc.gov/nip/recs/provisional_recs/hpv.pdf. Accessed November 9, 2006.

[59] American Academy of Pediatrics, et al. Human papillomaviruses. In: Pickering LK, Baker C], Long SS, editors. Red book: 2006 report of the Committee of Infectious Diseases. 27th edition. Elk Grove Village (IL): American Academy of Pediatrics; 2006. p. 473-6.

[60] Carpenter CF, Gandhi TK, Kong LK, et al. The incidence of ehrlichial and rickettsial infection in patients with unexplained fever and recent history of tick bite in central North Carolina. $\mathrm{J}$ Infect Dis 1999;180(3):900-3.

[61] O'Leary DR, Marfin AA, Montgomery SP, et al. The epidemic of West Nile virus in the United States, 2002. Vector Borne Zoonotic Dis 2004;4(1):61-70.

[62] Barnard DR, Xue RD. Laboratory evaluation of mosquito repellents against Aedes albopictus, Culex nigripalpus, and Ochierotatus triseriatus (Diptera: Culicidae). J Med Entomol 2004;41(4):726-30.

[63] O'Reilly M, Paddock C, Elchos B, et al. Physician knowledge of the diagnosis and management of Rocky Mountain spotted fever: Mississippi, 2002. Ann N Y Acad Sci 2003;990: 295-301.

[64] Helmick CG, Bernard KW, D'Angelo L. Rocky Mountain spotted fever: clinical, laboratory, and epidemiological features of 262 cases. J Infect Dis 1984;150(4):480-8.

[65] Treadwell TA, Holman RC, Clarke M, et al. Rocky Mountain spotted fever in the United States, 1993-1996. Am J Trop Med Hyg 2000;63(1-2):21-6.

[66] Herwaldt BL, McGovern PC, Gerwel MP, et al. Endemic babesiosis in another eastern state: New Jersey. Emerg Infect Dis 2003;9(2):184-8.

[67] Steere AC, Sikand VK, Meurice F, et al. Vaccination against Lyme disease with recombinant Borrelia burgdorferi outer-surface lipoprotein A with adjuvant. Lyme Disease Vaccine Study Group. N Engl J Med 1998;339(4):209-15.

[68] Couch P, Johnson CE. Prevention of Lyme disease. Am J Hosp Pharm 1992;49(5): 1 164-73. 
[69] des Vignes F, Piesman J, Heffernan R, et al. Effect of tick removal on transmission of Borrelia burgdorferi and Ehrlichia phagocytophila by Ixodes scapularis nymphs. J Infect Dis 2001;183(5):773-8.

[70] Falco RC, Fish D, Piesman J. Duration of tick bites in a Lyme disease-endemic area. Am J Epidemiol 1996;143(2):187-92.

[71] Nadelman RB, Nowakowski J, Fish D, et al. Prophylaxis with single-dose doxycycline for the prevention of Lyme disease after an Ixodes scapularis tick bite. N Engl J Med 2001;345(2): 79-84.

[72] Kazakova SV, Hageman JC, Matava M, et al. A clone of methicillin-resistant Staphylococcus aureus among professional football players. N Engl J Med 2005;352(5):468-75.

[73] Lindenmayer JM, Schoenfeld S, O'Grady R, et al. Methicillin-resistant Staphylococcus aureus in a high school wrestling team and the surrounding community. Arch Intern Med 1998; 158(8):895-9.

[74] Nguyen DM, Mascola L, Brancoft E. Recurring methicillin-resistant Staphylococcus aureus infections in a football team. Emerg Infect Dis 2005; 11(4):526-32.

[75] Gawande A. On washing hands. N Engl J Med 2004;350(13):1283-6.

[76] McBryde ES, Bradley LC, Whitby M, et al. An investigation of contact transmission of methicillin-resistant Staphylococcus aureus. J Hosp Infect 2004;58(2):104-8.

[77] Mast EE, Goodman RA, Bond WW, et al. Transmission of blood-borne pathogens during sports: risk and prevention. Ann Intern Med 1995;122(4):283-5.

[78] Gantz N, Harmon H, HandyJ. Methicillin-resistant Staphylococcus aureus infections among competitive sports participants-Colorado, Indiana, Pennsylvania, and Los Angeles County, 2000-2003. MMWR Morb Mortal Wkly Rep 2003;52(33):793-5.

[79] Workowski KA, Berman SM. Sexually transmitted diseases treatment guidelines, 2006. MMWR Recomm Rep 2006;55(RR-1 1): 1-94.

[80] Holmes KK, Levine R, Weaver M. Effectiveness of condoms in preventing sexually transmitted infections. Bull World Health Organ 2004;82(6):454-61.

[81] Wingood GM, DiClemente R, Mikhail I, et al. A randomized controlled trial to reduce HIV transmission risk behaviors and sexually transmitted diseases among women living with HIV: the WiLLOW Program. J Acquir Immune Defic Syndr 2004;37(Suppl 2):S58-67.

[82] Wald A, Langenberg AG, Link K, et al. Effect of condoms on reducing the transmission of herpes simplex virus type 2 from men to women. JAMA 2001;285(24):3100-6.

[83] Winer RL, Hughes JP, Feng Q, et al. Condom use and the risk of genital human papillomavirus infection in young women. N Engl J Med 2006;354(25):2645-54.

[84] French PP, Latka M, Gollub EL, et al. Use-effectiveness of the female versus male condom in preventing sexually transmitted disease in women. Sex Transm Dis 2003;30(5):433-9.

[85] Gross M, Buchbinder SP, Holte S, et al. Use of reality "female condoms" for anal sex by US men who have sex with men. HIVNET Vaccine Preparedness Study Protocol Team. Am J Public Health 1999;89(1 1):1739-41. 